\title{
Avaliação da Aprendizagem e Atuação Docente
}

\author{
NADIA APARECIDA DE SOUZA \\ Doutora em Educação, professora da Universidade Estadual de Londrina e \\ integrante do Núcleo de Estudos e Pesquisas em Avaliação Educacional \\ nadia@uel.br
}

\begin{abstract}
Resumo
Visando a superar as formas tradicionalmente desenvolvidas para a formação continuada dos educadores que atuam no Primeiro Ciclo do Ensino Fundamental, principalmente o que tange às questões relativas ao processo de avaliação da aprendizagem, desenvolveu-se uma investigação na linha da pesquisa ação em uma escola pública estadual. Na construção de uma nova concepção e prática avaliativa, pela reflexão no e sobre o próprio fazer, em uma constante interação teoria-prática, as professoras elaboraram, analisaram e implementaram um Projeto de Avaliação; (re)elaboraram planejamentos, adequando-os aos resultados auferidos nos processos de avaliação implementados; (re)edificaram novas práticas pedagógicas objetivando superar as dificuldades que identificaram no processo de apropriação do conhecimento, na tentativa de promover uma maior regulação do processo de aprendizagem. Apesar das dificuldades encontradas no decorrer da experiência vivenciada, o desenvolvimento do processo de formação continuado no interior da escola, embasado na análise das especificidades do contexto, das dificuldades do cotidiano escolar e das proposições teóricas que fundamentam e orientam o saber e o fazer docente, evidenciou-se como caminho promissor na construção de uma prática avaliativa comprometida com a aprendizagem do aluno e com a promoção de alternativas pedagógicas destinadas à melhoria do processo de ensino.

Palavras-chave: formação de professores, avaliação da aprendizagem, ensino e aprendizagem.
\end{abstract}

\section{Resumen}

Con la idea de superar las formas tradicionalmente desarrolladas para la formación continuada de los educadores que actuan en el Primer Ciclo de la Enseñanza Primaria, principalmente en lo que se refiere a cuestiones relativas al proceso de evaluación del aprendizaje, se desarrolló una investigación en el campo de pesquisa-acción en una escuela pública del Estado. Para construir una nueva concepción y práctica evaluativa, a través de la reflexión teórico-prática, en y sobre la propia actuación, las profesoras elaboraron, analizaron e implementaron un Proyecto de Evaluación; reelaboraron planificaciones, adecuándolas a los resultados recogidos en los procesos de evaluación aplicados y reconstruyeron nuevas prácticas pedagógicas con el objetivo de superar las dificultades identificadas en el proceso de apropiación del conocimiento, con la idea de conseguir controlar mejor el proceso de aprendizaje. A pesar de las dificultades encontradas en el transcurso de la experiencia vivida, el desarrollo del proceso de formación continuada en el interior de la escuela, apoyado en el análisis de las particularidades del contexto, de las 
dificultades de la rutina escolar y de las proposiciones teóricas que fundamentan y orientan el saber y la actuación docente, demostró ser un camino con futuro, en la construcción de una práctica evaluativa comprometida con el aprendizaje del alumno y con la promoción de alternativas pedagógicas destinadas a la mejoría del proceso de enseñanza.

Palabras-clave: formación de profesores, evaluación del aprendizaje, enseñanza y aprendizaje.

\begin{abstract}
Aiming to overcome traditionally developed ways for the continuing formation of educators who work in the First Cycle of Elementary School (grades 1 through 4), mainly concerning evaluation of the learning process, an investigation was conducted in the way of action in a public school. While constructing a new evaluative conception and practice, through reflection on the actual "doing", the educators created, analyzed and implemented an Evaluation Project; they (re)devised their planning, making them adequate to the results obtained in the evaluation processes implemented; and they (re)built pedagogical practices to overcome the difficulties they identified in the process of knowledge appropriation, in an effort to promote a better regulation of the learning process. Despite all difficulties encountered in the course of the experiment, the development of the continued education process inside the school, based on the analysis of the specificities of the context, of the difficulties of daily school life and of the theoretical propositions that underlie and guide the educator's knowledge and actions, proved to be a promising path in the construction of a new evaluation practice committed to the student's learning process and to the promotion of pedagogical alternatives intended to improve the teaching process.

Key-words: teacher formation, learning evaluation, teaching and learning.
\end{abstract}


A implantação do Ciclo Básico de Alfabetização, em 14 de março de 1988, pelo Decreto $n^{\circ} 2545$, marcou o início de uma caminhada para a reorganização da escola pública paranaense em face da "necessidade de reversão do insucesso escolar nas séries iniciais do Primeiro Grau, que resulta em evasão e repetência" (Paraná, 1988a).

A proposta de ampliação do tempo de alfabetização elaborada pela Secretaria de Estado da Educação do Paraná pretendia criar condições, tanto na programação curricular quanto na organização da escola, que permitissem a permanência de um número maior de alunos por um período maior de tempo no espaço escolar e que garantissem a progressão continuada dos estudantes no domínio do saber sistematizado, sem as limitações que acabam por desrespeitar os ganhos de aprendizagem já efetivados por eles (Paraná, 1988b). Assim, no suceder das fases que integram o Ciclo - inicialmente de dois anos e posteriormente de quatro não há ocorrência de reprovações.

Entretanto, não basta promover automaticamente o aluno por entre as fases que integram o Ciclo, é necessário muito mais se o compromisso do educador for baseado na promoção das condições necessárias à apropriação, pelo educando, das "aprendizagens essenciais, com o domínio de habilidades e atitudes de busca de novas informações e conhecimentos" (Oliveira, 1998, p. 9).

Assim, a avaliação da aprendizagem, para promover as conseqüências estruturais desejadas, deve assumir um sentido mais amplo e profundo, analisando o aproveitamento escolar com base em uma teoria de ensino e aprendizagem; deve ser repensada em função do processo educativo do qual é parte integrante; deve avocar a função pedagógica de apoio ao aperfeiçoamento dos processos de ensino e aprendizagem, subsidiando o diagnóstico dos problemas que dificultam ao aluno apropriar-se do saber proposto e fundamentando as intervenções pedagógicas necessárias à promoção das condições que favoreçam o pleno desenvolvimento do educando.

Concebendo a avaliação da aprendizagem enquanto um processo dinâmico voltado para o diagnóstico das aprendizagens efetivadas e das falhas a serem superadas no decorrer das relações de ensino e aprendizagem, a prática pedagógica desloca a preocupação do produto para o processo, da classificação para a construção do saber, do autoritarismo docente para o pluralismo e responsabilidade compartilhada por todos aqueles envolvidos na tarefa educativa.

A avaliação passa a ter por objeto principal a transformação e a elaboração de novas etapas de desenvolvimento cognitivo. Perceber as dificuldades como superáveis e o conhecimento como um processo em 
construção significa reconhecer as muitas possibilidades de transformação do contexto social e das relações que nele se estabelecem.

A mudança nunca se afigurou fácil, pois, se no campo do saber as transformações se verificam, geralmente, de forma acelerada, no campo do fazer, muitas vezes, os obstáculos se interpõem e as zonas de conflito e resistência se instalam.

A dificuldade na efetivação de mudanças conceituais e práticas em relação à avaliação da aprendizagem constitui obstáculo à reorganização da ação docente no atendimento aos interesses e necessidades do aluno, porquanto, na ausência de elementos que indiquem a caminhada por ele empreendida na construção do saber e dos problemas por ele vivenciados na apropriação do conhecimento, os professores não dispõem de dados que subsidiem a reflexão sobre a ação desenvolvida e a reorganização das atividades de ensino. Desse modo, sem elementos para analisarem e julgarem as ações passadas, eles permanecem impossibilitados de estruturarem as ações futuras.

Planejar o futuro tendo por fundamento a análise do passado e suas repercussões no presente, pressupõe a implementação de ações que mudem a realidade, imprimindo-lhe uma nova perspectiva. Assim, para a concretização do sonho na transformação do ideal em real faz-se necessário o compromisso do educador com a reflexão crítica acerca da prática avaliativa, especialmente no contexto de um projeto educacional que carece congregar em um continuum de quatro anos todas as condições materiais e metodológicas pelas quais assegure a edificação de uma base sólida de conhecimentos.

Todavia, a superação das distorções e incoerências ainda presentes na prática avaliativa exige a possibilidade - pela promoção de espaço e tempo no contexto das instituições - e o compromisso dos educadores com a reflexão crítica acerca da ação pedagógica que desenvolvem. Ao adquirirem o hábito de pensar coletivamente sobre os problemas que emergem do cotidiano escolar, eles conseguirão abrir espaços e tempos no contexto das instituições de ensino para a superação das ações fundamentadas no senso comum.

Assim, apesar das grandes transformações confirmadas no plano teórico, da proposição e implementação de novas propostas políticopedagógicas, pouco se verificou enquanto mudança efetiva no quadro epistêmico e atitudinal do professor em sala de aula, de forma que, muitas vezes, a avaliação

"é praticada na perspectiva do disciplinamento, mas parece que é no sentido pedagógico; está sendo praticada a favor da seletividade, mas parece estar sendo a favor da promoção do educando; está sendo praticada com base em fatores externos 
ao processo de ensino e aprendizagem dos conteúdos essenciais, mas parece estar sendo a favor do ensino, da aprendizagem e do crescimento do educando. A ilusão se faz realidade." (Luckesi, 1992, p. 526)

A nova proposta político-pedagógica implementada pelo governo paranaense, objetivando a reversão do quadro de repetência e evasão, pelo repensar da escola em sua totalidade e pela "eliminação da reprovação" (Paraná, 1988a) ao promover um "prolongamento do tempo de alfabetização" (Paraná, 1988a) no interior do ciclo de ensino, resultou de um novo quadro epistêmico que passou a exigir uma série de mudanças conceituais e práticas por parte do corpo docente das escolas públicas estaduais (Paraná, 1988b).

A avaliação da aprendizagem, neste contexto, tem importância fundamental para a viabilização das metas tracejadas, uma vez que, longe de constituir um momento estanque e sentencioso no interior da prática educativa, deve assumir um sentido mais amplo e profundo, analisando o aproveitamento escolar com base em uma teoria de ensino-aprendizagem, possibilitando e fundamentando a reorganização do processo pedagógico, bem como favorecendo a superação das dificuldades encontradas na aquisição e construção do conhecimento.

Alterar uma prática avaliativa até então classificatória, pontual, autoritária e passar a perfilhar a avaliação enquanto indicador diagnóstico dos progressos apresentados pelo aluno, com a finalidade de permitir a compreensão do processo de construção do conhecimento por ele vivido, bem como a criação de alternativas pedagógicas para a melhoria do processo de ensino, exige, do professor, o confronto constante entre seu fazer cotidiano e as proposições que emergem do campo teórico.

A dificuldade em extrapolar modelos com base nos quais edificaram seus referencias de ação e a complexidade da tarefa de concretizar, na realidade escolar, as metas propostas no plano teórico exigem o envolvimento de todos os profissionais da rede pública de ensino na construção de uma escola voltada para a compreensão da educação, inserida em um tempo e em um contexto e entendida como espaço de elaboração e reelaboração do saber e de formação do sujeito social, que pode contribuir para a construção de uma sociedade menos desigual quando comprometida com a permanência da população que nela ingressa. Exigem, ainda, que o professor se reconheça como aprendiz e co-autor de sua própria formação, perceber-se como construtor do conhecimento na interação com o objeto.

Assim, a reconstrução da prática avaliativa reclama pensar o professor enquanto aprendiz e co-autor de sua formação, superando as propostas e práticas centradas nos discursos, nas regras e normas distantes 
do cotidiano escolar, que são muitas vezes implementadas linear e acriticamente; determina pensar o professor enquanto um profissional que, na interação com o outro, com o ambiente e com o objeto do conhecimento, constrói e reconstrói o próprio saber e o próprio fazer.

Antes de se constituir em simples receptor passivo de informações a serem reproduzidas na realidade de trabalho, longe de se constituir em mero executor de ações concebidas por outros, faz-se necessário que o professor se construa, também, enquanto profissional que reflete criticamente sobre a prática desenvolvida, desvelando as concepções a ela inerentes e reconstruindo-a, teoricamente fundamentado, de um modo gradual e progressivo (Alarcão, 1996).

Somente a partir do pensar e repensar do próprio fazer e dos fundamentos que o determinam será possível a apreensão de novos saberes e o exercício de novos fazeres. Assim, o professor precisa - individual e coletivamente - ampliar os espaços de reflexão, de construção e reconstrução de novos conhecimentos e de novas formas de ação, especialmente no concernente à avaliação da aprendizagem - foco maior de nosso estudo - de maneira a, gradualmente, conquistar um exercício profissional autônomo e consciente (Nóvoa, 1995).

Assim, foi realizado estudo buscando:

a) compreender a forma como as teorias direcionam a ação do educador no que concerne à avaliação da aprendizagem e das aprendizagens possíveis de serem edificadas tendo por origem e fundamento a prática concretizada no cotidiano escolar (objetivo de conhecimento); e

b) aprimorar a ação pedagógica dos professores envolvidos pela ampliação e maior entendimento dos fundamentos teóricos necessários ao desvelamento e compreensão da prática desenvolvida no decorrer do processo de (re)construção coletiva do Projeto de Avaliação (objetivo prático).

O caminho escolhido na promoção da unicidade teoria-prática foi o da mediação possível a ser estabelecida por meio de pesquisa-ação, que se processa sempre no sentido de ser "orientada em função da resolução de problemas ou de objetivos de transformação" (Thiollent, 1988, p. 7) e, ainda, de "aumentar o conhecimento dos pesquisadores e o conhecimento do 'nível de consciência' das pessoas e grupos considerados" (Thiollent, 1988 , p. 16), na certeza de que a compreensão da realidade, pelo desvelamento dos fundamentos que a determinam, pode processar-se enquanto mudanças na situação concreta - na prática - são progressiva e continuadamente introduzidas (Carson, 1990). 
A pesquisa foi desenvolvida de março de 2000 a dezembro de 2001, em uma escola pública de médio porte, localizada no perímetro urbano da cidade de Londrina, Estado do Paraná, e envolveu os profissionais que integram o grupo que atua no Primeiro Ciclo do Ensino Fundamental, perfazendo um total de 18 (dezoito) pessoas, sendo 15 (quinze) professoras e 3 (três) especialistas (orientadora educacional, supervisora de ensino e coordenadora pedagógica).

Determinar os procedimentos possíveis de serem implementados na construção de uma nova prática avaliativa exigiu o levantamento e análise dos documentos oficiais - leis, decretos, indicações, deliberações, resoluções e, ainda, o Currículo Básico - produzidos a partir de 1987. No contexto escolar, fez-se necessário analisar o Projeto Político-Pedagógico e os instrumentos destinados ao registro de desempenho dos alunos - Ficha de Acompanhamento e Parecer Parcial -, mais uma vez no intuito de melhor explicitar aspectos inerentes à prática avaliativa.

Para saber um pouco mais sobre os profissionais que participaram do projeto, inicialmente foi proposto um questionário estruturado objetivando o levantamento de dados pessoais e informações gerais sobre regime de trabalho, condição em que o professor assumiu a fase, formação e participação em cursos de aperfeiçoamento.

Posteriormente, para acompanhamento do processo de pesquisaação foram desenvolvidas entrevistas semi-estruturadas, propondo questionamentos básicos, fundamentados em teorias e hipóteses interessantes ao estudo e que garantissem amplo campo para novos questionamentos frente às respostas manifestas.

Ainda, para acompanhamento do processo de pesquisa-ação foi efetivada observação direta do cotidiano, com objetivos delimitados: coletar situações de avaliação da aprendizagem que se processam no interior de cada sala de aula, para que subsidiassem reflexões posteriores, sob a forma de Estudos de Caso. As observações foram registradas por meio de relatos descritivos dos fatos e situações destacados em decorrência da relevância que representavam para o tema objeto de estudo.

Finalmente, devido à opção pela pesquisa-ação foram promovidos espaços coletivos, que constituíram lócus de interlocução e reflexão, de discussão teórica e reelaboração da prática, no decorrer dos quais objetivou-se a ampliação dos elos de interdependência entre os participantes.

O primeiro espaço coletivo foi o dos Círculos de Trabalho que foram estruturados de maneira a viabilizarem-se em três momentos distintos, mas articulados: momento de diálogo, voltado para a apropriação do saber acumulado, a ser criticamente analisado pelos participantes à medida que 
avançavam nas reflexões sobre a prática avaliativa; momento de ação, centrado na atividade dos participantes no desenvolvimento de práticas avaliativas fundamentadas nas discussões precedentes, viabilizando no interior da sala de aula as propostas produzidas coletivamente; e momento de reflexão, tendo por objetivo favorecer a contínua aprendizagem pela reflexão constante, pela progressiva integração entre teoria e prática, pelo resgate e (re)elaboração das experiências construídas e reconstruídas que se convertem em novos saberes.

O segundo espaço coletivo foi o das Reuniões por Fase, momento de interlocução e reflexão mais restrito, pois era voltado especificamente para as peculiaridades e temáticas de cada uma das fases que integravam o Ciclo.

A análise dos dados coletados no decorrer da pesquisa efetivou-se pela categorização das informações em torno de dois eixos temáticos: a relação teoria-prática na (re)construção de um Projeto de Avaliação e as transformações da prática pedagógica em decorrência das alterações da prática avaliativa.

\section{NA MORADA DO SONHO... O RECANTO REAL}

"Na vida, há limites e entendimentos que só o tempo elucida. E mais: o tempo vergado por rachaduras do dia-a-dia, recolhido em grãos de envolvimento, incandescido na forja do destemor." (Pecci, 1986, p. 56)

No decorrer dos anos o professor parece ter sido colocado no vértice e no vórtice de relações sociais contraditórias. Assim, se em alguns momentos apresenta-se como um personagem indispensável à sociedade ao desempenhar, inclusive, algumas funções educativas antes reservadas unicamente às famílias -, em outros momentos é desvalorizado pelo sistema social e é responsabilizado pelo fracasso que caracteriza o processo educacional.

Nesse contexto, é importante lembrar que o sistema político que transforma a educação em uma bandeira - a desfraldar as oportunidades de democratização da sociedade pela garantia de permanência na escola e pela promoção de um processo educativo que favoreça a apropriação do saber sistematizado - tem consciência do risco e do incômodo que representa uma população instruída, crítica e participativa.

Assim, o lento e persistente desqualificar do professor no exercício de sua profissão parece consistir um dos mecanismos empreendidos na 
garantia da imutabilidade do quadro de exclusão - se não do contexto escolar, pelo menos da apropriação do saber sistematizado - que vem se perpetuando em nossa sociedade. Por conseguinte, não podemos estranhar a dinâmica singular inerente às políticas públicas de propor projetos educacionais e dificultar a sua execução, de valorizar a ação pedagógica e promover entraves à sua consecução, de oferecer com uma das mãos para, então, retirar com a outra.

"Não é por falta de vontade, pois é inerente ao professor o desejo de ensinar, de formar, de contribuir para a construção de um futuro melhor; não é por resistência ao novo, pois gostamos das novidades, queremos alterar nossa forma de trabalho e acredito que o trabalho foi sendo realizado por todas as professoras é uma prova disso. A grande dificuldade é a falta de conhecimentos e a conseqüente insegurança para o desenvolvimento de uma prática pedagógica que produza os resultados desejados." (Lucinei - Impressões Pessoais, setembro de 2001)

A necessidade de aperfeiçoamento constitui certeza presente na maioria das professoras, de forma que quando as possibilidades são ofertadas, quando o processo de formação continuada acontece no interior da escola, fundamentado na análise das especificidades do contexto, das dificuldades do cotidiano e das proposições teóricas que orientam o saber e o fazer docente, propicia as bases necessárias à construção de uma prática avaliativa comprometida com a efetiva apropriação crítica e significativa do saber sistematizado pelo educando e para a criação de alternativas pedagógicas destinadas à melhoria do processo de ensino.

\section{Na tecitura do sonho... o vicejar do real}

No transcorrer de 2000, enquanto as discussões acerca da avaliação da aprendizagem ocupavam o espaço e o tempo das Oficinas Pedagógicas, no interior das salas de aula novas práticas - avaliativas e pedagógicas conquistavam outros espaços e tempos.

"Nas oficinas pedagógicas e nas reuniões por fase fomos percebendo as nossas dificuldades e fomos buscando juntas as possibilidades de superação. Nada foi dado pronto. Nós fomos construindo juntas as soluções para os nossos problemas, conforme íamos identificando os problemas. Nós estudamos, discutimos, testamos e analisamos as nossas hipóteses. Depois, estudávamos e discutíamos novamente tentando corrigir as dificuldades que ainda existiam." (Neusa - Impressões Pessoais, setembro de 2001) 
Quase nada foi imposto... Todo o trabalho efetivado resultou das necessidades que se apresentavam, das dificuldades que se interpunham, dos sonhos que construíamos e das ações que desenvolvíamos almejando transformar ideal em real, principalmente porque precisamos aprender a construir o conhecimento; adquirindo a "capacidade de utilizar o pensamento como atribuidor de sentido" (Alarcão, 1996, p. 175).

Precisamos, igualmente, superar a prática rotineira e muitas vezes desprovida de significado - porque decorrente de impulsos irrefletidos ou de hábitos arraigados -, aprendendo a refletir, a direcionar nossa vontade, nosso pensamento, nosso questionamento e nossa curiosidade na elucidação das questões interpostas pelo cotidiano do fazer docente, e reconhecendo que a reflexão constitui "um processo lógico e psicológico, que combina a racionalidade da lógica investigativa com a irracionalidade inerente à intuição e à paixão do sujeito pensante; que une cognição e afetividade num ato específico, próprio do ser humano" (Alarcão, 1996, p. 175).

Em síntese, precisamos nos reconhecer em formação, e, portanto, detentores de conhecimentos e de práticas, construídas em nossa trajetória acadêmica e constantemente reconstruídas no transcorrer de nosso exercício pedagógico.

Por conseguinte, cada um de nós detinha o direito de ter os saberes e os fazeres reconhecidos enquanto fundamento na edificação e reedificação de novos saberes e fazeres, de ter aceita a capacidade de tomar nas próprias mãos a gestão do processo de aprendizagem que vivenciava, de recuperar a própria voz pelo recobro da capacidade de organizar, executar e avaliar a própria ação, reorganizando-a contínua e progressivamente.

"Acredito que as mudanças somente foram possíveis porque o processo que vivenciamos nos fez analisar e re-analisar tudo que fazíamos com o que dizíamos. Nos jogos, nos estudos de caso e nas atividades práticas cada uma de nós era obrigada a confrontar-se consigo mesma, com as próprias ações, o que nos obrigava a tentar mudar. Mas, para mudar precisávamos aprender outras coisas, o que nos obrigava a estudar e tentar encontrar na teoria os elementos para resolver os problemas que estávamos enfrentando." (Nina - Impressões Pessoais, setembro de 2001)

O processo de edificação da autonomia pedagógica vivenciado pelos professores prescindia de atitudes autoritárias e diretivas. Conseqüentemente, aprender não poderia decorrer da mera apresentação de informações que alguém julgasse necessárias. 
Era preciso gerar a apropriação de novos saberes na transformação dos fazeres, muitas vezes cristalizados na rotina corrosiva do dia-a-dia: era necessário promover a confrontação entre o discurso manifesto - porque este é muito mais facilmente transformável - com a prática consubstanciada no interior da sala de aula, gerando o conflito e a contradição, porque então se tornaria possível "reconhecer o problema que necessita de explicação" (Schön, 1995, p. 85).

Aprender, obrigatoriamente, tinha de ser a construção e reconstrução de respostas para questões emersas da atividade desenvolvida, na edificação e reedificação de práticas capazes de suscitar as transformações desejadas.

Ainda, aprender tinha de ser a apropriação do referencial teórico que atuasse enquanto corpo de conhecimentos a fundamentar a contextualização e priorização de metas e, conseqüentemente, a orientar a organização da ação pedagógica, a subsidiar a análise de sua consecução e a possibilitar sua adequação em decorrência das necessidades e problemas diagnosticados.

"Foi interessante ir observando as mudanças que iam sendo produzidas na prática das professoras, mudanças que aconteceram porque:

$\checkmark \quad$ Estudamos a teoria, mas pela compreensão que ela poderia lançar sobre a prática desenvolvida e pelas transformações que poderia gerar auxiliando na superação das dificuldades identificadas;

Durante a prática fomos percebendo a importância de pensar sobre o que estava acontecendo, porque o processo já fornece indicadores sobre o produto;

$\checkmark \quad$ Reconhecemos que as mudanças na prática avaliativa auxiliavam na compreensão das dificuldades do aluno e na reorganização da atividade pedagógica." (Lucinei - Entrevista, maio de 2001)

A prática pedagógica era a fonte de conhecimento, porque fundamento para a reflexão e para a proposição de alterações. Portanto, os estudos teóricos apenas propiciavam "instrumentos de análise e reflexão sobre a prática, sobre como se aprende e sobre como se ensina" (Solé e Coll, 1996, p. 12).

Os estudos teóricos somente se revestem de relevância e significação quando enunciam alguma explicação acerca das interrogações emersas dos percalços tão presentes no cotidiano da prática pedagógica e, também, da possibilidade dessa explicação permitir uma maior compreensão das implicações da ação docente no processo de formação do educando.

Assim, as metas propostas pela pesquisa-ação foram se consolidando no contexto escolar, enquanto os professores reedificavam a capacidade de atuar como autores e co-autores da história, no 
reconhecimento de sua capacidade e responsabilidade com o próprio desenvolvimento, com a própria auto-superação. E na conquista de sua autonomia profissional, os professores conquistavam, ainda, a capacidade de articular a razão com a realidade, desvelando os múltiplos determinantes que os condicionam e ao contexto no qual vivem.

Instalava-se, então, o hábito de refletir criticamente na ação e sobre a ação desenvolvida. Mas, ao analisar o passado - as práticas avaliativas e pedagógicas consubstanciadas - os professores almejavam projetar o futuro pela superação das dificuldades ainda existentes. Assim, analisar e compreender uma dada realidade, sob a luz dos pressupostos teóricos que a fundamentam e explicam, facultou o desvelamento do próprio passado, pela compreensão de suas implicações no presente, e possibilitou, no tracejar do futuro, o delineamento das conseqüências desejadas ao nível da ação.

Transformações foram ocorrendo na prática avaliativa, que assumiu paulatinamente o sentido de

"processo que permite a compreensão dos problemas de aprendizagem dos alunos $e$ que possibilita a elaboração de intervenção na promoção da construção do conhecimento pelo aluno." (Ermínia - Impressões Pessoais, setembro de 2001)

Mas as transformações não se limitaram à prática avaliativa; elas se propagaram atingindo a organização das situações de ensino. Os professores foram resgatando e reedificando continuadamente sua capacidade de pensar, executar e avaliar a própria ação. Planejar tornou-se um exercício incessante que resultou na transformação das práticas pedagógicas consolidadas em sala de aula, ainda que nem sempre no ritmo e na amplitude desejados.

Assim, os professores, superando as limitações decorrentes do processo de formação vivenciado e subjugando as restrições impostas pelas condições de trabalho, aprenderam a identificar as dificuldades que emergiam no dia-a-dia e a refletir sobre elas, para que, pela análise das condições existentes, pudessem estabelecer hipóteses de solução a serem implementadas e reprogramadas no cotidiano escolar. Era a edificação da práxis pedagógica,

"práxis na qual a ação e a reflexão, solidárias, se iluminam constante e mutuamente. Na qual a prática, implicando a teoria da qual não se separa, implica também uma postura de quem busca o saber; e não de quem passivamente o recebe." (Freire, 1975, p. 80) 
O processo de avaliação da aprendizagem representava um ponto nodal nesse contexto, uma vez que transformar a prática avaliativa era reverter o jogo do faz de conta, pois os professores, ao aprenderem a problematizar o cotidiano, o óbvio e as muitas práticas rotineiras que executavam, descobriram que novos conhecimentos, novos caminhos e novas formas de fazer as coisas eram possíveis de serem desenvolvidas.

Foi refletindo na ação e sobre a ação que a teoria assumiu um sentido de significação e funcionalidade - ela auxiliava na resolução das questões que se interpunham no cotidiano docente; foi refletindo na ação e sobre a ação que os professores foram alcançando formas de edificar seu saber e seu fazer no que tange à avaliação da aprendizagem, até porque aprenderam significativamente e "a teoria assumiu um significado prático, enquanto a prática assumiu um significado teórico" (Mônica - Impressões Pessoais, setembro de 2001).

"A avaliação da aprendizagem passou a ser, para mim, um processo de investigação na vida e sobre a vida do aluno na escola, num processo de conscientização e exploração do ele já sabe, pela análise de suas potencialidades, limites e ritmo específico. A avaliação da aprendizagem, portanto, deixou de ser dar provas e atribuir notas, deixou de ser separar os bons alunos dos maus alunos e passou a ser um processo de transformação da sala de aula num círculo de investigação constante e num espaço para o aperfeiçoamento da minha atividade." (Nina - Entrevista, maio de 2001)

Sinuoso, mas incitante, o trajeto perscrutado no edificar da práxis avaliativa fez conhecer possibilidades outras pela transformação do contexto escolar em face das necessidades que suscitou pela modificação, também, da prática pedagógica. Até porque, os professores envidaram seus esforços para orientar os processos de ensino e aprendizagem para o domínio dos conhecimentos, ajustando as ações e as intervenções que desenvolviam na efetivação das metas estabelecidas e considerando as peculiaridades inerentes ao aluno e ao grupo.

"A avaliação não pode ser, apenas, para aprovar ou reprovar o aluno, mas deve ser realizada para diagnosticar as suas aprendizagens e as dificuldades que sente. Mas, eu não posso apenas diagnosticar, eu preciso reorganizar as atividades de ensino visando garantir a aprendizagem. Portanto, eu tenho que ter objetivos claros e planejar e re-planejar bem para poder garantir que os alunos aprendam." (Creusa - Impressões Pessoais, setembro de 2001)

Assim, reorganizar o ambiente da sala de aula e introduzir alterações na prática pedagógica não foi uma exigência, mas uma 
necessidade provocada pelas vivências experienciadas e pelas transformações que eram, então, desencadeadas pelas mudanças introduzidas na prática avaliativa e na assunção do planejamento enquanto uma atividade intencional que congrega a fixação de metas aos meios para atingi-las (Luckesi, 1995).

Tortuoso, mas instigante, o percurso explorado na construção de uma prática avaliativa verdadeiramente comprometida com a apropriação do saber pelo educando, promoveu alterações profundas, apesar de lentas e graduais, nos procedimentos de ensino implementados pelos professores. Alterações que transformaram as práticas pedagógicas e não apenas as modernizaram.

Árduo, mas excitante, o percurso explorado na construção da práxis avaliativa e da práxis pedagógica promoveu, ainda, o estreitamento dos laços de solidariedade e comprometimento entre os professores, pelo amadurecimento das idéias e consensos necessários às transformações almejadas; que assegurou o reconhecimento e valorização da diversidade, da pluralidade e da especificidade que caracterizam a composição do "nós" na integração dos muitos "eus".

"Aprendemos muito mais que conceitos e técnicas para melhor avaliarmos ou para melhor ensinarmos; aprendemos a trocar experiências, a expressar dúvidas, a compartilhar soluções para os problemas que enfrentamos e que um pouco de paciência, atenção e carinho podem provocar grandes mudanças." (Ermínia Impressões Pessoais, setembro de 2001)

No processo de construção e reconstrução das práticas avaliativas, os professores foram construindo um significado próprio e pessoal para um sem número de saberes e fazeres que marcavam o seu cotidiano profissional. Essa construção pessoal foi sendo orientada para desvelar os fundamentos teóricos que direcionam a ação docente, para que sua compreensão favorecesse seu emprego de múltiplas e variadas formas e, ainda, para que seu domínio permitisse a conquista de uma maior autonomia na edificação da práxis avaliativa e da práxis pedagógica.

O diálogo foi o caminho tracejado, "diálogo que é sempre comunicação e se funda na co-laboração", sem possibilitar espaço para a "conquista", mas apenas para a "adesão [...] a verificar-se na intercomunicação dos homens, mediatizados pela realidade" (Freire, 1999, p. 166-7)

Partilhamos saberes e experiências, confrontamos opiniões e discutimos posicionamentos, questionamos a realidade tal qual se apresentava, delineamos sonhos estabelecendo novos horizontes, debatemos princípios e contestamos assertivas, vivenciamos novas 
experiências, nos lançamos em novas tarefas, sempre refletindo sobre a ação desenvolvida, na certeza de que "o conhecimento se constitui nas relações de transformação e se aperfeiçoa na problematização crítica destas relações" (Freire, 1975, p. 36).

\section{No canteiro de sonhos}

Uma tentativa de pensar e repensar a formação do educador na perspectiva da unicidade teoria-prática. Uma tentativa de mudar saberes e fazeres no compartilhar de saberes e fazeres pelo desenvolvimento de uma pesquisa-ação.

Opção um pouco árdua, espinhosa, porque exigiu adequar o próprio ritmo ao daqueles que caminham conosco pela vereda escolhida; porque obrigou a compartir-se sem perder a inteireza; porque requereu persistência, sensibilidade e muita atenção para que cada momento fosse usufruído e transformado em oportunidade de reflexão crítica e coletiva e de reconhecimento de indicadores para a mudança; porque demandou humildade, condição indispensável para o diálogo, para a construção compartilhada e solidária.

Mas, também, opção incitante e afável, porque permitiu que cada um e todos se descobrissem capazes de aprender novos saberes, iluminando a prática e revivificando-a progressiva e continuadamente; conferiu-nos novos olhares - mais apurados e intencionais - que nos possibilitaram contemplar e melhor compreender a realidade que circunscreve o nosso ser e o nosso agir e que pode se metamorfosear na consecução laboriosa do nosso sonho de transformação, e pudemos, então, elaborar nossas próprias hipóteses de solução para os problemas que vivenciávamos e testá-las na prática.

Refletindo sobre os resultados que produziam, pudemos elaborar outras hipóteses que conduziram a novas reflexões, a novos estudos e pesquisas; experienciar o valor pedagógico do erro na reedificação do saber, quando nos consentimos experimentar alternativas de ação e, conscientizando-nos dos percalços, tentamos novamente, de uma outra maneira, em um constante reencontrar o outro para reencontrar-se nele "dessa forma o e e e o tu passam a ser [...] dois tu que se fazem dois eü" (Freire, 1999, p. 165-6, grifos do autor); porque ocasionou a exploração dos sonhos e desejos, das aspirações e motivações latentes em cada um de nós, no reconhecimento dos muitos limites e possibilidades inerentes a cada um e à realidade de trabalho. 
Os resultados positivos foram inúmeros e decorreram de um trabalho coletivo desenvolvido na tentativa de transformar a própria história. Uma ponte foi, assim, construída transformando sonho em realidade.

Assim, os conhecimentos relativos ao processo de avaliação da aprendizagem ampliaram-se e suscitaram transformações na prática avaliativa desenvolvida, bem como alterações profundas na atitude do professor quanto ao comprometimento com a aprendizagem efetiva do educando.

Ao reconhecer a importância do processo de aprendizagem na edificação do produto, os professores gradualmente mudaram as ações que implementavam no cotidiano escolar, tornando-as mais individualizadas, no atendimento das dificuldades específicas de cada aluno, e mais diversificadas, na tentativa de tornar mais significativa e crítica a apropriação dos novos conhecimentos.

Ainda, uma nova concepção do erro, pela compreensão de sua função no processo de construção do conhecimento, determinou alterações no processo de interação entre os professores e os alunos, suscitando a necessidade de promover atividades individualizadas em atenção às dificuldades específicas de cada um.

Ao compreenderem a função do erro no contexto dos processos de ensino e aprendizagem, os professores desenvolveram uma maior tolerância para as dificuldades evidenciadas pelas crianças na apropriação do saber e passaram a implementar atividades que, centrando-se nos problemas identificados, favoreciam o confrontar de hipóteses, o permutar de informações, a experimentação de situações diversificadas.

Nesse contexto, os professores auxiliares passaram a desempenhar um papel basilar e, alterando gradativamente sua maneira de atuação, deixaram o fundo da sala de aula - onde normalmente corrigiam cadernos e mais cadernos - e passaram a dedicar-se ao acompanhamento dos alunos na consecução das atividades desenvolvidas numa maior integração com o professor regente.

Também, os conhecimentos relativos ao processo de apropriação do saber estenderam-se e aprofundaram-se, suscitando alterações nas práticas pedagógicas desenvolvidas.

As atividades promovidas na efetivação dos processos de ensino e aprendizagem foram sendo transformadas - ainda que muitas vezes de maneira ainda tímida e incipiente - e conquistaram o interior da sala de aula na forma de práticas socializadas, que facilitavam a troca de informações entre as crianças, e que, fundamentadas no uso de materiais concretos, favoreciam a compreensão dos princípios enunciados. 
Outrossim, o planejamento adquiriu um novo significado no cotidiano escolar enquanto "atividade intencional pela qual se projetam fins e se estabelecem meios para atingi-los" (Luckesi, 1995, p. 105).

As professoras passaram a planejar, reedificando a capacidade de conceber, executar e avaliar as próprias ações na viabilização dos processos de ensino e aprendizagem. Mas, planejar não ficou restrito à elaboração, execução e avaliação de planos de ensino, mas abarcou também a análise da proposta curricular pela redelimitação dos conteúdos mínimos a serem trabalhados em cada uma das fases que integram o Primeiro Ciclo, num processo que vem sendo reestruturado continuamente.

Outras alterações decorrentes das aprendizagens edificadas ganharam forma. Assim:

a) o Projeto de Avaliação foi elaborado coletivamente, traduzindo uma prática que se consubstanciava no cotidiano da atividade docente;

b) uma série de instrumentos - grades de observação, fichas de desempenhos, fichas de acompanhamento, pareceres parciais foram elaborados e reelaborados pelos professores, numa tentativa de resignificar os objetivos de ensino no contexto da prática avaliativa e de melhor compreender o processo de apropriação do conhecimento vivenciado pelo aluno;

c) os vínculos de solidariedade e comprometimento se ampliaram e se fortaleceram, traduzindo-se em ações compartilhadas que passaram a ser desenvolvidas pelos professores, principalmente entre aqueles que atuavam na mesma fase;

d) o hábito de refletir na prática e sobre a prática principiou a se incorporar no cotidiano. Os professores passaram a pesquisar a própria prática, reedificando-a à medida que estabeleciam novas hipóteses para a solução dos problemas diagnosticados, na tentativa de aprimorar os processos de ensino e aprendizagem.

Como pesquisadores, também aprendemos que:

a) a vivência compartilhada de experiências e conhecimentos, na unicidade da relação teoria-prática deve ser o caminho privilegiado na formação do educador;

b) a crítica deve ser comedida, pois só podemos efetivamente analisar a realidade vivenciada pelo outro quando a experimentamos com a mesma intensidade que ele;

c) o olhar intencional e o ouvir atento permitem distinguir as sutilezas dos gestos e das falas, auxiliando numa intervenção 
mais consistente com as necessidades que emergem das situações interpostas pelo cotidiano;

d) um processo de construção coletivo não é linear nem constante, mas marcado por avanços e recuos, por contradições e conflitos, por encontros e desencontros. Entretanto, apesar de tudo, ele é progressivo e contínuo;

e) o preparo cuidadoso de cada momento é fundamental para o pleno usufruir daquilo que será, então, o momento presente. Mas, o planejar diligente significa também a ampliação da capacidade de ousar, de superar o estabelecido, na adequação criativa do concebido ao novo que cada situação propõe;

f) a universidade ainda faz pouco. É necessário mergulhar na realidade educacional para, compreendendo-a, poder ensinar segundo essa realidade;

g) desvelar as contradições que permeiam as políticas educacionais é um dos momentos do processo de superação do quadro de desigualdades, exclusão e segregação tão presentes em nossa sociedade;

h) refletir criticamente no e sobre o fazer exercitado, pela integração teoria-prática, nos permite construir novos saberes e reedificar novos fazeres, num processo infindável que se propaga e se expande qual uma espiral progressiva e contínua, que nos desafia permanentemente a ir além, a superar o estabelecido e realizar novas conquistas;

No conjunto, finalmente, a pesquisa possibilitou desvelar um caminho para a formação do professor enquanto pesquisador de seu fazer. Ao aprenderem a contemplar o passado, analisado suas ações, os professores que participaram do estudo conquistaram a possibilidade de compreendê-las em seu lócus de viabilização e de transformá-las, estabelecendo fins e aclarando propósitos.

Ao aprenderem a refletir sobre suas práticas, os professores alcançaram aptidão para elaborar hipóteses de solução para os problemas que vivenciavam e de reelaborá-las pelo perscrutar persistente de seus resultados.

Ainda, ao aprenderem a construir seu saber em confronto com seu fazer e a edificar seu fazer em confronto com seu saber, os professores compreenderam a dinamicidade do conhecimento e a provisoriedade das aprendizagens, em decorrência, mesmo, de sua limitação a um tempo e a um contexto.

Destarte, ao tornarem-se pesquisadores de suas próprias práticas, os professores passaram a integrar-se na realização de pesquisas conjuntas 
sobre o próprio fazer, construindo espirais pelo estabelecimento de elos de interdependência e reciprocidade entre teoria e prática, num pertinaz esforço de compreender as situações que experienciavam em seu cotidiano pedagógico - porque passaram a conceber, executar, avaliar, refletir, replanejar -, num processo continuado de superação do próprio saber e do próprio fazer, na certeza de que as novas sínteses são sempre provisórias portanto novas síncrises - e exigem o laborioso e persistentes pesquisar da própria ação no aprimoramento gradual de seus resultados.

\section{REFERÊNCIAS BIBLIOGRÁFICAS}

ALARCÃO, I. Reflexões críticas sobre o pensamento de D. Schön e os programa de formação de professores. In: ALARCÃO, I. (org.) Formação reflexiva de professores estratégias de supervisão. Porto: Porto, 1996, p. 9-40.

CARSON, T. What kind of knowing is critical action research? In: Theory Into Practice, v. 29, n. 3, p. 167-173, 1990.

FREIRE, P. Extensão ou comunicação. Rio de Janeiro: Paz e Terra, 1975. 93p.

FREIRE, P. Pedagogia do oprimido. 26. ed. Rio de Janeiro: Paz e Terra, 1999. 184p.

LUCKESI, C. C. Avaliação da aprendizagem escolar. São Paulo: Cortez, 1995. 180p.

NÓVOA, A. A. Formação de professores e profissão docente. In: NÓVOA, A. A (coord.). Os professores e sua formação. 2. ed. Lisboa: Dom Quixote, 1995b. p. 15-33.

OLIVEIRA, Z. M. R. Avaliação da aprendizagem e progressão continuada: bases para a construção de uma nova escola. Estudos em Avaliação Educacional, n. 18, p. 7-12, 1998.

PARANÁ. Decreto $n^{\circ}$ 2545, 14 mar.1988. Institui o Ciclo Básico de Alfabetização nas escolas de Primeiro Grau da rede estadual de ensino. 1988a.

PARANÁ. Resolução $n^{\circ}$ 744, 22 mar. 1988. Autoriza e regulamenta o Ciclo Básico de Alfabetização nas escolas de Primeiro Grau da rede estadual de ensino. 1988b. 
PECCI, J. C. O ramo de hortênsias. São Paulo: Círculo do Livro, 1986. 151p.

SCHÖN, D. A. Formar professores como profissionais reflexivos. In: NÓVOA, A. Os professores e sua formação. 2. ed. Lisboa: Dom Quixote, 1995. p. 77-92.

SOLÉ, I.; COLL, C. Os professores e a concepção construtivista. In: COLL, C. et al. O construtivismo em sala de aula. São Paulo: Ática, 1996, p. 10-28.

THIOLLENT, M. Metodologia da pesquisa-ação. São Paulo: Cortez: Autores Associados, 1988. 108p.

Recebido em: dezembro 2003 Aprovado para publicação em: março 2004 